\title{
The relationship between the phase interface valence electron structure of Mg-Al alloy and mechanical properties
}

\author{
Yan jie, Xie jun \\ Hebei University of Architecture
}

Keywords: electron density; the valence electron structures of the interface; interfacial stress

\begin{abstract}
It is found that the electron density of $\gamma$-Mg17Al12(110) $\| \mathrm{Mg}$ - $\mathrm{Al}(0001)$ interfaces declines gradually with increasing $\mathrm{Al}$ element, namely interfacial electron density declines.Compared with $\gamma$-Mg17Al12(110) \| Mg-Al(0001) interfaces, Mg2Si(001)\|Mg-Al(0001) has greater interfacial stress, that is to say the strengthening effect of Mg2Si to Mg-Al alloys is greater than $\gamma$-Mg17Al12(110) to Mg-Al alloys. Obviously it is interfacial consolidation under higher intensity scale or greater stress.
\end{abstract}

\section{1、 introduction}

The influence of Different phase interface on alloy has been noticed for a long time. The valence electron structures of the interface between different phases is not only refer to the net work of both sides and the electron of net work ,but also to the average covalence electron density $\rho_{(h k l)}, \rho_{(u v w)}$, The difference electron density $\Delta \rho$ andAtomic state group number which made difference electron density $\sigma$. The higher phase interface electronic density, the stronger interfacial bonding. The lower difference electron density $\Delta \rho$, the better electron density continunity; On the contrary, has higher interfacial stress. When the stress is larger than a certain value, the continuous electron density is destroyed, which will be accompanied by new phase formation or fracture of the material [1].

From the calculation, it is found that the heterogeneous electron density interface in solid solution is less than $10 \%$, but most of solid solution and compound interface of heterogeneous electron density is more than $10 \%$, and the atomic state group number $\sigma$ which keeps continuous present big difference. electron density of consecutive number of sets of atomic state sigma. The change on the electronic structure will directly affect the nature of the interface and lead to the performence of alloy[1].

After the grain boundaries discontinuous precipitation to a certain extent, Mg17Al12 with fine flake form along the (0001) growth.Accordingly, the Al content in the matrix is declining, the lattice constant increases continuously, and the lattice constant change is continuous

The latest research results show that there are three kinds of AZ91 Mg alloy precipitation phase morphology: lath-shaped, hexagonal prism, short rod-like. The lath-shaped precipitation phase hold 90\% percent, with thick particle, lieing low Mg (0001) fundarmental plane. Therefore, this kind of precipitated phase particles cannot be effectively hinder the dislocation slip on the surface of the base, ageing strengthening effect is poor. Instead, because hexagonal prism and base level orthogonal, short rod and base oblique. So, is beneficial to hinder the dislocation glide base surface, which is advantageous to the ageing strengthening, but the amount is too little, increaseing the number of this phase is one of the effective ways to improve the strength of this kind of alloy.

This paper will tell the caluculation model and method of $\mathrm{Mg}-\mathrm{Al}$ alloy and valence electron structure, calculate the valence electron structure of the interfacial precipitates and probe the influence of interface valece electron structure on mechanical property and alloying element alloying behavior.

\section{Calculation on $\gamma$-Mg17Al12(110)//Mg-Al(0001) interface valence electron structure}

In Mg-Aalloy, $\gamma$-Mg17Al12(110) has various phase relationship with its primary structure,such 
$\gamma$-Mg17Al12 ${ }^{(1 \overline{1} 1)} / / \mathrm{Mg}^{-\mathrm{Al}}{ }^{(\overline{2} 110)}$ and so on. Calculation on Interface valence electron structure and its binding factor through $\gamma$-Mg17Al12 的 (110) phase plane and Mg-Al alloy cardinal plane

2.1Covalence electron density on $\gamma$-Mg17Al12(110).

The selected Crystal plane unit should have the property of translation symmetry . Precipitates in the alloy of $\gamma$-Mg17Al12 unit (110) plane as shown in figure 1.

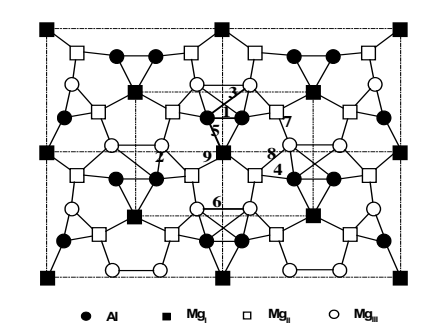

Figure $1 \gamma-\mathrm{Mg}_{17} \mathrm{Al}_{12}$ unit cell (110) reference unit

There are nine covalent bonds in $\gamma$-Mg17Al12(110) surface, There are $D_{1}^{\mathrm{Al}-\mathrm{Al}}$ 、 $D_{2}^{\mathrm{Mg}}{ }^{\mathrm{MII}-\mathrm{Al}}$ 、

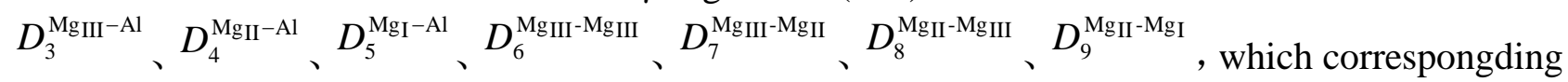

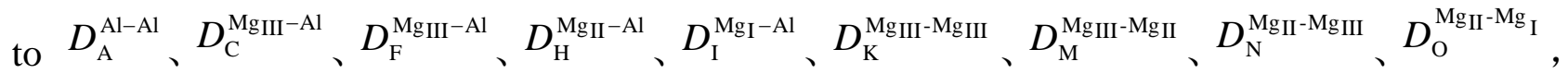
therefore the Covalence electron number of nine bonds can be anylised through EET theory BLD anylsis. The nine experimental $\gamma$-Mg17Al12(110) bond length and its equal bond work is listed as:

$$
\begin{aligned}
& D_{1}^{\mathrm{Al}-\mathrm{Al}}=2.6583, \quad I_{1}^{\mathrm{Al}-\mathrm{Al}}=4 \times 1 \times 1=4 ; \\
& D_{2}^{\mathrm{Mg}_{\mathrm{III}}-\mathrm{Al}}=2.9063, \quad I_{2}^{\mathrm{Mg}_{\mathrm{III}}-\mathrm{Al}}=4 \times 1 \times 2=8 \text {; } \\
& D_{3}^{\mathrm{Mg}_{\mathrm{III}}-\mathrm{Al}}=4.4587, \quad I_{3}^{\mathrm{Mg}}{ }^{\mathrm{IIII}-\mathrm{Al}}=4 \times 1 \times 2=8 \text {; } \\
& D_{4}^{\mathrm{Mg}{ }^{\mathrm{II}}-\mathrm{Al}}=3.4298, \quad I_{4}^{\mathrm{Mg}_{\mathrm{II}}-\mathrm{Al}}=4 \times 1 \times 2=8 \text {; } \\
& D_{5}^{\mathrm{Mg}_{\mathrm{I}}-\mathrm{Al}}=3.2225, \quad I_{5}^{\mathrm{Mg}^{-}-\mathrm{Al}}=4 \times 1 \times 2=8 \text {; } \\
& D_{6}^{\mathrm{Mg} I I-\mathrm{Mg}_{\mathrm{III}}}=4.3010, I_{6}^{\mathrm{Mg}_{\mathrm{III}}-\mathrm{Mg}_{\mathrm{III}}}=4 \times 1 \times 1=4 \text {; } \\
& D_{7}^{\mathrm{Mg}_{\text {III- }}{ }^{-\mathrm{Mg}_{\mathrm{II}}}}=2.9618, \quad I_{7}^{\mathrm{Mg}_{\mathrm{III}}-\mathrm{Mg}_{\mathrm{II}}}=4 \times 1 \times 2=8 \text {; } \\
& D_{8}^{\mathrm{Mg}_{\text {II }}-\mathrm{Mg}_{\text {III }}}=3.5100, \quad I_{8}^{\mathrm{Mg}_{\mathrm{II}}-\mathrm{Mg}_{\mathrm{III}}}=4 \times 1 \times 2=8 \text {; } \\
& D_{9}^{\mathrm{Mg}_{\mathrm{II}}{ }^{-\mathrm{Mg}_{\mathrm{I}}}}=3.3472, \quad I_{9}^{\mathrm{Mg}_{\mathrm{II}}-\mathrm{Mg}_{\mathrm{I}}}=2 \times 2 \times 2=8 \text { 。 } \\
& \sum n_{\mathrm{c}}^{\gamma-\mathrm{Mg}_{17} \mathrm{Al}_{12}(110)}=\mathrm{nAI} 1+\mathrm{nBI} 2+\ldots+\mathrm{nII9}
\end{aligned}
$$

The dimension of (110) crastal plane: ${ }_{(110)}^{\gamma-\mathrm{Mg}_{17} \mathrm{Al}_{12}}=\sqrt{2} a_{0}^{2}$

The Covalence electron density of $\gamma$-Mg17Al12(110) crystal face $\rho_{(110)}^{\gamma-\mathrm{Mg}_{17} \mathrm{Al}_{12}}=\sum n_{\mathrm{c}}^{\gamma-\mathrm{Mg}_{17} \mathrm{Al}_{12(110)}} / S_{(110)}^{\gamma-\mathrm{Mg}_{17} \mathrm{Al}_{12}}$

The Covalence electron density of Mg-Alalloy (0001) crystal face 


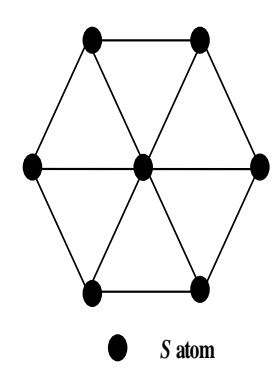

Figure $2 \mathrm{Mg}-\mathrm{Al}$ alloy (0001) crystal face

The reference unit of Mg-Al alloy crystal unit (0001) surface is listed in Figure 5-2,whichexist two negligible Covalence electron, They are $D_{n 1}^{S-S}, D_{n 2}^{S-S}$, which correspond to phase space Covalence electron $D_{n \mathrm{~B}}^{S-S}, D_{n \mathrm{E}}^{S-S}$, Therefore the Covalence electron number can be provided through EET theory BLD anylysis. The experimental bond length and theIdentical bond number on (0001) crystal surface are:

$$
D_{n 1}^{S-S}=\mathrm{a}_{0}, \quad I_{1}=18 ; D_{n 2}^{S-S}=\sqrt{3} a_{0}, \quad I_{2}=12 \text { 。 }
$$

The sum reference Covalence electron number of (0001) crystal surface is:

$$
\sum n_{\mathrm{c}}^{\mathrm{Mg}-\mathrm{Al}(0001)}=\mathrm{nCI} 1+\mathrm{nDI} 2
$$

The reference unit dimension of Mg-Alunit (0001) surface:

$$
S_{(0001)}^{\mathrm{Mg}-\mathrm{Al}}=3 \sqrt{3} / 2 a_{0}^{2}
$$

The electron density of Mg-Al unit (0001) surface:

$$
\rho_{(0001)}^{\mathrm{Mg}-\mathrm{Al}}=\sum n_{\mathrm{c}}^{\mathrm{Mg}-\mathrm{Al}(0001)} / S_{(0001)}^{\mathrm{Mg}-\mathrm{Al}}
$$

\section{3 calculation of $\Delta \rho, \sigma$ and $\sigma^{\prime}$}

Accoring to its definition,the interfaceformed fromalloy phase $\gamma$-Mg17Al12 and Mg-Al(0001) $\gamma(110) / / \alpha(0001)$ are:

$$
\Delta \rho=\frac{\left|\rho_{(110)}^{\gamma-\mathrm{Mg}_{17} \mathrm{Al}_{12}}-\rho_{(0001)}^{\mathrm{Mg}-\mathrm{Al}}\right|}{\left(\rho_{(110)}^{\gamma-\mathrm{Mg}_{17} \mathrm{Al}_{12}}+\rho_{(0001)}^{\mathrm{Mg}-\mathrm{Al}}\right) / 2} \times 100 \%
$$

According to contiunuous ability of $\Delta \rho, \sigma$ and $\sigma^{\prime}$ is calculated.

\section{The result of $\gamma$-Mg17Al12(110)//Mg-Al(0001) interface valence electron structure}

The Interface bonding factor of $2 \mathrm{wt} \% \mathrm{Al}$ is listed in chart l:

From chart 1,when containing $\mathrm{Al} \mathrm{2wt \% ,} \mathrm{The} \mathrm{dimension} \mathrm{of} \mathrm{Mg}-\mathrm{Al}(0001) \mathrm{S}=0.2676$, the total valence electron $\sum_{\mathrm{c}}^{n^{\mathrm{S}}}=1.8857$, the interface electron density $\rho=7.0464$, the total valence electron of $\mathrm{Mg}-\mathrm{Al}$ alloy $\Sigma \mathrm{nc}=7.7768$ 。 The dimension of $\mathrm{Mg} 17 \mathrm{Al12}(110)$ is 1.5770, he total valence electron $\sum n_{\mathrm{c}}^{\mathrm{s}}=6.6711$, the interface electron density $\rho=4.2302$, the total valence electron of $\mathrm{Mg}-\mathrm{Al}$ alloy $\Sigma \mathrm{nc}$ $=47.5993$ 。

For easy anylysis, Interface bonding factor of $\rho$ and $\Delta \rho$ containing $3 \sim 10 \mathrm{wt} \%$, are listed in chart 2. 


\section{Acknowlegement}

We are grateful for thefinancial support of the outstanding youth fund of science and technology of Hebei,China(Project No. YQ2014003) and scientific research fund program of Hebei University of Architecture (Project No. Q-201320)

\section{References}

1 Glelloto S. The study of continuous precipitation in Mg-9wt\%Al-1\%wtZn alloy. Acta Materialia, 2000, 48: 1775-1787

2 Liu Weidong, Liu Zhilin, Qu Hua. Calculation of $\gamma$-TiAl alloy valence electron structure and mecanical property. Rare Metal Materials and Engineering

3 , 2003, 32(11): 902-906

4 Yu Ruihuang. Analysis of valence electronic structure of Al Mg alloy phase diagram, two yuan delta phase and -Mg17Al12 phase. Natural Science Journal of Jilin University, 1979(4), 52-72

5 Wei Aili, Fu Zhen. Production and application of Mg alloy . Foundry equipment research , 2003(1): 34-36

6 Luo A. Pekguleryuz M O Cast magnesium alloys for elevated temperature application- $n$. J Mater Sci, 1994, 29(20): 5259-5271

7 Zhang Jin, Zhang zonghe. Magnesium alloys and its application. Beijing: Verlag Chemie GmbH , 2004

8 Xiao Xiaoling, Luo Chenping. AZ91 The Mg-Al alloy - (Mg17Al12) precipitation phase morphology and crystallography. Acta Metallurgica Sinica, 2001, 37(1): 1-7

9 Luo Chengping, Xiao Xiaoling, Liu jiangwen. AZ91Mg-Al alloy $\gamma$-Mg17Al12 precipitated phase multiple phase relation andPseudo twinrelationship. Acta Metallurgica Sinica, 2002, 38(7): 709-714

10 Chen Zhenhua. wrought magnesium alloys. Beijing: Chemical Industry Press, 2005 